\title{
Decolorization of Methylene Blue in an Ar Non-Thermal Plasma Reactor
}

\author{
Khanit Matra* and Sittinum Tawkaew
}

Electrical Engineering Department, Engineering Srinakharinwirot University, Nakhin Nayok 26120, Thailand

Received 11 March 2019; Accepted 19 February 2020

\begin{abstract}
The decolorization of methylene blue (MB) dye wastewater was performed via atmospheric Ar non-thermal plasma (ArNTP). Investigations were carried out into two main aspects of the model; hydrogen peroxide (H2O2) production and the decolorization of MB by Ar-NTP. It was found that $\mathrm{H} 2 \mathrm{O} 2$ could be obtained better at a lower $\mathrm{pH}$ and with a higher Ar gas flow rate and plasma power. The decolorization rate constant of $\mathrm{MB}$ decreased with the increase in the solution $\mathrm{pH}$, and it was found to follow a pseudo-first-order reaction. The optimum experimental conditions in this paper for the decolorization of a 5 ppm initial MB concentration were: $20.35 \mathrm{~W}$ plasma power, 4 LPM Ar gas flow rate, and $\mathrm{pH} 5$, together with the addition of $920 \mathrm{ppm} \mathrm{Fe} 2+$. The decorization rate constant was $83.7 \times 10-3$ min-1, which was 9.73 times greater than that without the addition of $\mathrm{Fe} 2+$ under the same experimental conditions.
\end{abstract}

Keywords: Argon plasma, Non-thermal gas discharge, Methylene blue, Decolorization, Water treatment.

\section{Introduction}

Nowadays, dye wastewater is one of most serious problems in Thailand and requires an urgent solution due to its effects on the environment. Dye wastewater treatment can be generally performed utilizing conventional methods, such as filtration, chemical oxidation, Fenton oxidation, and biodegradation [1-5]. It has been reported that the biodegradation method is not suitable for dye wastewater treatment since the dye is toxic to microorganisms. Filtration or the coagulation process does not represent a dye degradation process, but can be used for separating dyes from wastewater to a solid phase. For chemical oxidation and Fenton oxidation, which are considered suitable methods for dye wastewater treatment, an oxidizing agent, such as hydrogen peroxide $\left(\mathrm{H}_{2} \mathrm{O}_{2}\right)$, is required for the oxidation process. Moreover, $\mathrm{H}_{2} \mathrm{O}_{2}$ can produce a hydroxyl radical $(\bullet \mathrm{OH})$, which is another powerful oxidizing agent for dye wastewater treatment [2], [6]. Recently, it was reported that both $\mathrm{H}_{2} \mathrm{O}_{2}$ and $\cdot \mathrm{OH}$ could be produced by a non-thermal plasma technique [7-11].

$\S$ Advanced oxidation processes (AOPs) at the interface between plasma and the liquid phase offer some advantages, and among these, atmospheric non-thermal plasma has recently been proposed as a promising technique for wastewater treatment [4], [9], [12-14]. Organic and inorganic matter could be removed from wastewater by oxidation via the reactions with ozone $\left(\mathrm{O}_{3}\right), \mathrm{H}_{2} \mathrm{O}_{2}, \cdot \mathrm{OH}$, and/or sulfate radicals $\left(\mathrm{SO}_{4}{ }^{\bullet}\right)$ during the advanced oxidative process [1416]. These active species can diffuse into the liquid phase, and chemically react with the organic and/or inorganic particles in the wastewater [12-15]. Moreover, owing to beneficial radical production and chemical reactions of AOPs by atmospheric non-thermal plasma, plasma technology has been continuously developed and applied in various fields, such as

*E-mail address: khanit@g.swu.ac.th

ISSN: 1791-2377 @ 2020 School of Science, IHU. All rights reserved.

doi:10.25103/iestr.131.15 nanostructure and nanomaterial synthesis, microorganism inactivation, biomedical treatment, agricultural enhancement, and air and water purification [7-8], [11], [17].

This research aimed to investigate the effect of atmospheric Ar non-thermal plasma (Ar-NTP) on the decolorization of methylene blue (MB) dye wastewater. A plasma model was simply designed, with the aim that it could be easily applied in a small dye wastewater treatment system. The electrical characteristics of the Ar-NTP, the discharge current, and the voltage are discussed herein. The influences of the solution $\mathrm{pH}$, Ar gas flow rate, and plasma power on $\mathrm{H}_{2} \mathrm{O}_{2}$ production, and on the decolorization of $\mathrm{MB}$ were studied. The effect of the addition of $\mathrm{Fe}^{2+}$ on the decolorization of MB was also investigated.

\section{Experimental Methods}

\subsection{Argon non-thermal plasma reactor setup}

A schematic drawing of the utilized Ar non-thermal plasma (Ar-NTP) system for dye wastewater treatment is illustrated in Fig. 1. The treatment system comprised three main parts: the plasma model, gas flow controller, and high-voltage power supply. For the plasma model, 6 pin electrodes with a diameter of $2 \mathrm{~mm}$ and length of $5 \mathrm{~mm}$ were bonded perpendicularly on a stainless steel rod, with a spacing of 10 mm between two pin electrodes. These pin electrodes were expected to help reduce breakdown voltage for plasma ignitions. The anode electrode was placed in an acrylic cylindrical chamber, which had a radius, thickness, and length of 15,2 , and $100 \mathrm{~mm}$, respectively. There were 6 holes on the surface of the chamber. The diameter of each hole was 1.25 $\mathrm{mm}$. Each hole in the acrylic chamber was located above each pin electrode's tip. The gap between the anode tip and hole was $2.5 \mathrm{~mm}$. A $10 \times 80 \mathrm{~mm}^{2}$ copper sheet was placed $5 \mathrm{~mm}$ above the anode tip and acted as the cathode and ground electrode. Argon (Ar) gas was provided from a gas cylinder with the flow rate controlled by a flow meter, and was fed in to the acrylic chamber via a plastic tube connected at both 
sides of the chamber. An in-house resonant AC power source was supplied to the anodes for Ar-NTP generation. The ArNTP model was placed in a $10 \times 30 \times 20 \mathrm{~cm}^{3}$ glass container and immersed under $2 \mathrm{~L}$ of MB solution. During the methylene blue treatment, the solution was circulated using a $600 \mathrm{~L} / \mathrm{h}$ water pump to achieve uniform treatment of the whole volume. In this time, the Ar-NTP was operated for $60 \mathrm{~min}$ at various input powers with a frequency around $66 \mathrm{kHz}$. The root mean square (rms) value and waveform of the discharge current $\left(\mathrm{I}_{\mathrm{d}}\right)$ and the voltage $\left(\mathrm{V}_{\mathrm{d}}\right)$ characteristics were inspected using an oscilloscope (Siglent SDS2304). To observe the $V_{d}$, a high-voltage probe (Pintek HVP-28HF) was connected across the Ar-NTP reactor. A one $\mathrm{k} \Omega$ monitoring resistor was placed between the cathode and ground for the $I_{d}$ measurement.

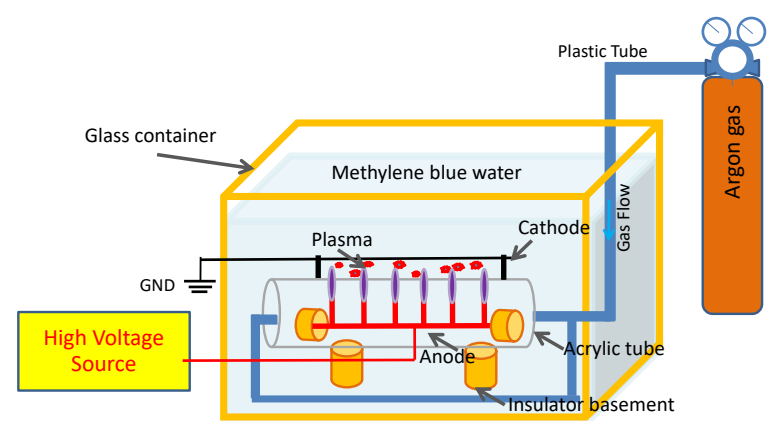

Fig. 1. (Color online) Plasma generation under MB wastewater.

\subsection{Measurement procedures for hydrogen peroxide} production and the decolorization of methylene blue

The concentration of $\mathrm{H}_{2} \mathrm{O}_{2}$ production was measured via the developing color during the reaction of $\mathrm{H}_{2} \mathrm{O}_{2}$ and the metavanadate ion $\left(\mathrm{VO}_{3}{ }^{-}\right)$as shown in Eq. $1 . \mathrm{H}_{2} \mathrm{O}_{2}$ reacts with the metavanadate anion $\left(\mathrm{VO}_{3}{ }^{-}\right)$in acid solution to form the peroxovanadium cation $\left(\mathrm{VO}_{2}{ }^{3+}\right)$. This measurement technique was modified from Nogueira et al. and Mahadevaiah et al [1819]. Typically, $10 \mathrm{~mL}$ of the sample was taken, and the color developed upon the addition of $5 \mathrm{~mL}$ of $0.015 \mathrm{M}$ ammonium metavanadate $\left(\mathrm{NH}_{4} \mathrm{VO}_{3}\right)$ and $5 \mathrm{~mL}$ of $3 \mathrm{M} \mathrm{H}_{2} \mathrm{SO}_{4}$. The solution was then made up with distilled water to a final volume of $25 \mathrm{~mL}$. The concentration of $\mathrm{H}_{2} \mathrm{O}_{2}$ was measured at $\lambda_{\max }=450 \mathrm{~nm}$ with a T80+UV-VIS spectrophotometer $(\mathrm{PG}$ Instruments Ltd.). A blank solution was prepared as a control following the same procedure as that for the developed color process, but distilled water was used instead of the sample

$\mathrm{VO}_{3}{ }^{-}+4 \mathrm{H}^{+}+\mathrm{H}_{2} \mathrm{O}_{2} \rightarrow \mathrm{VO}_{2}{ }^{3+}+3 \mathrm{H}_{2} \mathrm{O}$

For assessing the efficiency of MB treatment, the decolorization of the MB dye solution was measured with a T80+ UV-VIS spectrophotometer (PG Instruments Ltd.). The concentration of the dye was determined from the measured UV-VIS spectrum, using the maximum MB absorption at $\lambda_{\max }$ $=660 \mathrm{~nm}$.

\section{Results and discussion}

\subsection{Plasma and electrical characteristics}

Since the high-voltage source used was a resonant $\mathrm{AC}$ power source, the output voltage was influenced by the resistance, capacitance, and inductance of the plasma model, as well as the Ar gas flow rate. Therefore, the input power of the power source was used as a control parameter for convenience. In this paper, Ar-NTP was operated at the input power of 60,80 , and $100 \mathrm{~W}$ with a frequency around $66 \mathrm{kHz}$. The Ar gas flow rate was varied form 2 to 4 liter per minute (LPM). When the power source was applied to the plasma reactor, Ar-NTP under the methylene blue water was generated between the anode tip and methylene blue water. Fig. 2 shows an image of Ar-NTP generation under MB water. The plasma jet color was bright purple-blue. Six streamer-like plasma jets originate from the six anode pins, and inject through the holes of the Ar-NTP reactor into the MB water. The characteristics of plasma jets were a self-sustained AC corona discharge [2023]. From the experimental results, it was found that the longest and brightest plasma jets' lengths were found with the input power of $100 \mathrm{~W}$ and a 4 LPM Ar gas flow rate, which were $1.25 \mathrm{~cm}$, approximately. The diameter of the plasma jets was a little larger than the diameter of the anode pin. It could be observed that at the higher gas flow rate and input power, plasma jets could expand and inject into the solution better. While the plasma jets elongated and reached just around the exit holes of the Ar-NTP reactor for other cases. The temperatures of treated solution after 60 min treatment had just slightly increased from the temperatures of solution before treatment.

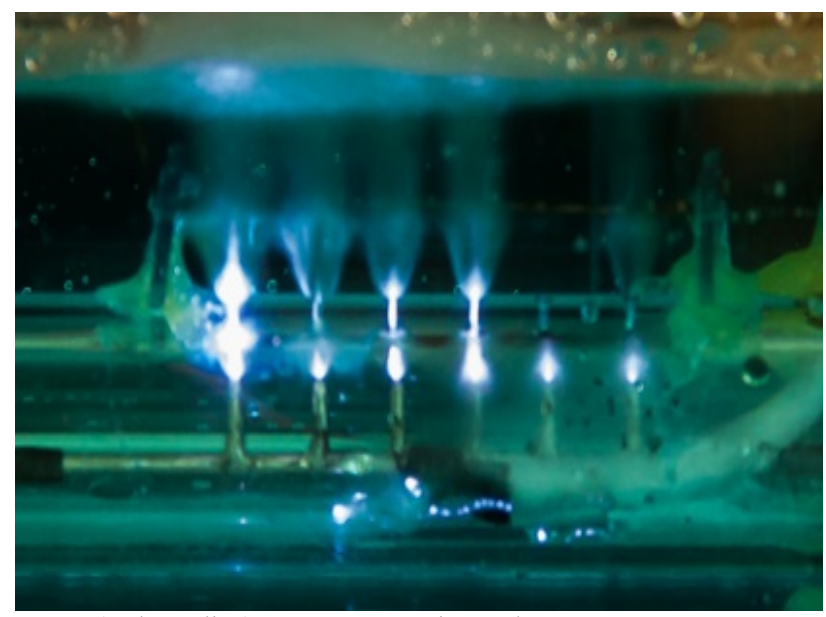

Fig. 2. (Color online) Ar-NTP generation under MB wastewater at an input power of $100 \mathrm{~W}$ and an Ar gas flow rate of 4 LPM.

An example of the discharge voltage and current waveforms during Ar-NTP generation under MB wastewater is presented in Fig. 3. The discharge waveforms under the other experimental conditions were also observed with similar characteristics, but the magnitudes of the parameters were different depending on the gas flow rate and power source input power. Owing to there being multi-anode pins, each anode pin generated its own discharge. Therefore, numerous micro discharge current pulses on each cycle could be noticed [12-13], [24-27]. The electrical discharge parameters of Ar-NTP generation under the various conditions are shown in Tab. 1 . It was noticed that at the same gas flow rate, the output power, $I_{d}$, and $V_{d}$ were slightly increased when the input power was increased, while at the same input power, the output power decreased when the gas flow rate was increased. Under the condition, in which ArNTP could be generated the most (as noted by the observed size and brightness of the plasma), the discharge current, voltage, and output power or plasma power were $48.56 \mathrm{~mA}_{\mathrm{rms}}$, 419.1 $\mathrm{V}_{\mathrm{rms}}$, and $20.35 \mathrm{~W}$, respectively.

\subsection{Influence of the plasma power and gas flow rate on the hydrogen peroxide production rates}

The influence of the Ar-NTP generating power and Ar gas flow rate on hydrogen peroxide $\left(\mathrm{H}_{2} \mathrm{O}_{2}\right)$ production were investigated. Fig. 4 a presents the effect of the Ar gas flow rate 
on $\mathrm{H}_{2} \mathrm{O}_{2}$ production with a fixed input power of $100 \mathrm{~W}$, and at $\mathrm{pH} 7$ of the $\mathrm{MB}$ water. The experimental results showed that an increase in the $\mathrm{Ar}$ gas flow rate could increase the concentration of $\mathrm{H}_{2} \mathrm{O}_{2}$. The highest $\mathrm{H}_{2} \mathrm{O}_{2}$ concentration was found with the largest $\mathrm{Ar}$ gas flow rate, namely 4 LPM. The $\mathrm{H}_{2} \mathrm{O}_{2}$ concentration in solution after 60 min treatment was $9.53 \times 10^{-3}, 12.53 \times 10^{-3}$, and $14.81 \times 10^{-3} \mathrm{ppm}$ at Ar gas flow rates of 2, 3 and 4 LPM, respectively. The concentration of $\mathrm{H}_{2} \mathrm{O}_{2}$ with the Ar gas flow rates of 3 and 4 LPM was improved by about 1.31 and 1.55 times that at 2 LPM, respectively.

Table 1. Discharge voltage and current for Ar-NTP generation under various conditions

\begin{tabular}{ccccc}
\hline $\begin{array}{c}\text { Argon } \\
\text { gas } \\
\text { flow } \\
\text { rate } \\
(\mathbf{L P M})\end{array}$ & $\begin{array}{c}\text { Input } \\
\text { power of } \\
\text { power } \\
\text { source } \\
(\mathbf{W})\end{array}$ & $\begin{array}{c}\text { Output } \\
\text { power } \\
\text { (plasma } \\
\text { power, } \\
\mathbf{W})\end{array}$ & $\begin{array}{c}\text { Discharge } \\
\text { voltage } \\
\left(\mathbf{V}_{\text {rms }}\right)\end{array}$ & $\begin{array}{c}\text { Discharge } \\
\text { current } \\
\left(\mathbf{m} \mathbf{A}_{\text {rms }}\right)\end{array}$ \\
\hline \multirow{2}{*}{2} & 60 & 15.39 & 364.1 & 42.27 \\
& 80 & 15.87 & 369.1 & 43.01 \\
& 100 & 16.39 & 373.1 & 43.94 \\
\hline \multirow{2}{*}{3} & 60 & 15.32 & 350.2 & 43.76 \\
& 80 & 16.65 & 379.9 & 43.83 \\
& 100 & 18.23 & 395.2 & 46.12 \\
\hline & 60 & 14.60 & 333.0 & 43.84 \\
& 80 & 18.86 & 393.5 & 47.93 \\
& 100 & 20.35 & 419.1 & 48.56 \\
\hline
\end{tabular}
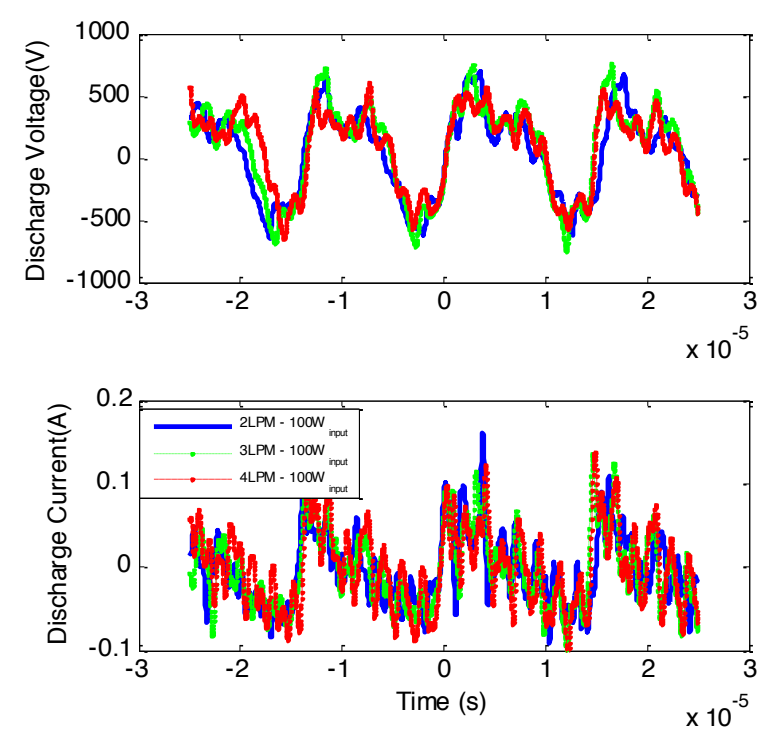

Fig. 3. (Color online) Real-time discharge voltage and current waveforms during Ar-NTP generation under MB wastewater at a $100 \mathrm{~W}$ input power and various gas flow rates.

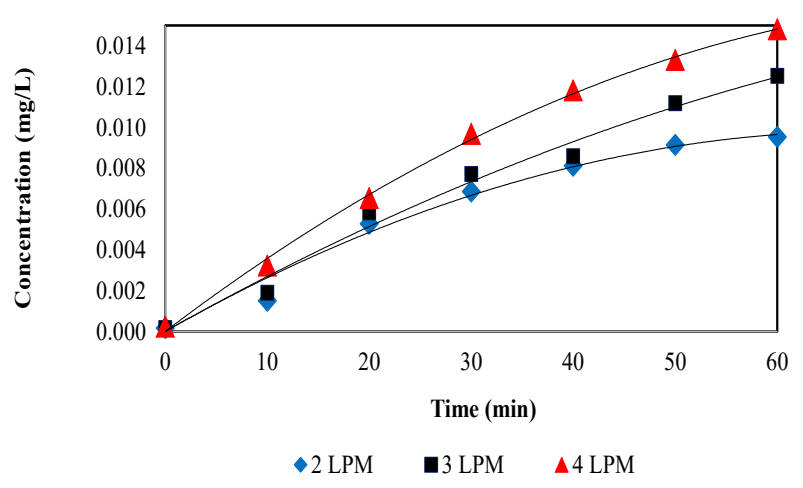

a)

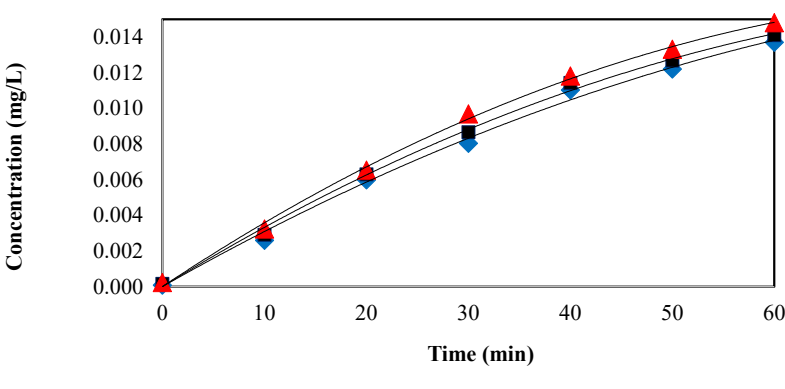

$\downarrow 60 \mathrm{~W}$ of input power $\quad \mathbf{\Delta} 80 \mathrm{~W}$ of input power $\Delta 100 \mathrm{~W}$ of input power

b)

Fig. 4. (Color online) a) Influence of the Ar flow rate at $100 \mathrm{~W}$ input power, and b) influence of plasma power at an Ar flow rate of 4 LPM on $\mathrm{H}_{2} \mathrm{O}_{2}$ production.

The evolution of $\mathrm{H}_{2} \mathrm{O}_{2}$ production as a function of plasma power at an Ar gas flow rate of 4 LPM is shown in Fig. 4b. It was expected that the concentration of $\mathrm{H}_{2} \mathrm{O}_{2}$ would be enhanced by increasing the plasma power as a result of the chemical equilibrium between the formation and destruction of $\mathrm{H}_{2} \mathrm{O}_{2}$ [28-30]. From the experimental results, it was indeed seen that an increase in the input power from 60 to 80 and 100 $\mathrm{W}$ could enhance the concentration of $\mathrm{H}_{2} \mathrm{O}_{2}$ in solution, with the $\mathrm{H}_{2} \mathrm{O}_{2}$ concentrations after 60 min treatment in each case $13.71 \times 10^{-3}, 14.10 \times 10^{-3}$, and $14.81 \times 10^{-3} \mathrm{ppm}$, respectively. However, it was noticed that the input power did not significantly affect the $\mathrm{H}_{2} \mathrm{O}_{2}$ production. This could possibly be due to the poor efficiency of the in-house power source, as could be noticed in Tab. 1. The output power of each input power was just about $25 \%$ of the input power, which hence needs to be improved. Since the increase in input power resulted in a slight difference in the output power, the $\mathrm{H}_{2} \mathrm{O}_{2}$ production was not significantly improved. However, the highest $\mathrm{H}_{2} \mathrm{O}_{2}$ concentration was found with the largest input power; therefore, this input power $(100 \mathrm{~W})$ was used for the rest of the experiments.

The principal oxidative species formed in the gas phase by the discharge are hydroxyl radicals $(\bullet \mathrm{OH})$ and hydrogen peroxide $\left(\mathrm{H}_{2} \mathrm{O}_{2}\right)$ [31-34]. The dominant reactions that take place in the plasma-liquid interface are listed as follows:

Excitation of Ar with a free electron

e- $+\mathrm{Ar} \rightarrow \mathrm{Ar}^{*}+\mathrm{e}-$

Interact of water with an electron

$\mathrm{H}_{2} \mathrm{O}+\mathrm{e}-\rightarrow \mathrm{H} \bullet+\cdot \mathrm{OH}+\mathrm{e}-$

Generation of radicals

$\mathrm{Ar}^{*}+\mathrm{H}_{2} \mathrm{O} \rightarrow \mathrm{Ar}+\bullet \mathrm{OH}+\mathrm{H} \bullet$

$\mathrm{H}_{2} \mathrm{O}_{2}, \mathrm{H}_{2}$, and $\mathrm{O}_{2}$ production

$\mathrm{H} \bullet+\mathrm{H} \bullet \rightarrow \mathrm{H}_{2}$

$\mathrm{HO} \bullet+\mathrm{HO} \bullet \rightarrow \mathrm{H}_{2} \mathrm{O}_{2}$

$\mathrm{HO} \bullet+\mathrm{H}_{2} \mathrm{O}_{2} \rightarrow \mathrm{HO}_{2} \bullet+\mathrm{H}_{2} \mathrm{O}$

$2 \mathrm{HO}_{2} \bullet \rightarrow \mathrm{H}_{2} \mathrm{O}_{2}+\mathrm{O}_{2}$

$\mathrm{H} \bullet+\mathrm{O}_{2} \rightarrow \mathrm{HO}_{2} \bullet$ 
$\mathrm{H}_{2}+\mathrm{HO} \bullet \rightarrow \mathrm{H}_{2} \mathrm{O}+\mathrm{H} \bullet$

$\mathrm{HO} \bullet+\mathrm{H} \bullet \rightarrow \mathrm{H}_{2} \mathrm{O}$

Ar* is generated during the plasma process (reaction in Eq. 2), and then reacts with interfacial water to generate hydrogen radical $(\mathrm{H} \bullet)$, and hydroxyl radical $(\bullet \mathrm{OH})$ (reaction in Eq. 4). Houria Ghodbane et al. suggested that the reaction in Eq. 2 is faster than the reaction in Eq. 3 for the generation of $\bullet \mathrm{OH}$ radicals in argon-water vapor mixtures [32]. The increase in the Ar gas flow rate could increase the concentration of Ar gas, which contribute to $\mathrm{Ar}^{*}$ production enhancement. The main reactions for $\mathrm{H}_{2} \mathrm{O}_{2}$ production are shown in Eq. 6, and Eq. 8. Joshi et al. suggested that that the reaction rate for the production of $\mathrm{H}_{2} \mathrm{O}_{2}$ obeys the zero-order rate law since the concentrations of $\mathrm{Ar}$ and water in reaction in Eq. 4 are constant during the experiment [31]. In addition, Liu et al. reported that the production rate of $\mathrm{H}_{2} \mathrm{O}_{2}$ depended on the applied current and voltage of the plasma source [2].

\subsection{Influence of solution $\mathrm{pH}$ on $\mathrm{H}_{2} \mathrm{O}_{2}$ production.}

The influence of the $\mathrm{pH}$ of the solution on $\mathrm{H}_{2} \mathrm{O}_{2}$ production

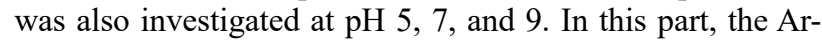
NTP generating plasma power and the Ar gas flow rate were fixed at $20.35 \mathrm{~W}$ and 4 LPM, respectively, due to the highest $\mathrm{H}_{2} \mathrm{O}_{2}$ production rate being obtained under these conditions as presented in the last section. The results of this experiment are shown in Fig. 5. The concentrations of $\mathrm{H}_{2} \mathrm{O}_{2}$ after 60 min treatment were $15.60 \times 10^{-3}, 14.50 \times 10^{-3}$, and $13.47 \times 10^{-3} \mathrm{ppm}$ at $\mathrm{pH} 5,7$, and 9 , respectively. It was noticed that a decrease in the solution $\mathrm{pH}$ seemed to enhance the production rate of $\mathrm{H}_{2} \mathrm{O}_{2}$. This is due to the fact that the low $\mathrm{pH}$ solution contains a high amount of $\mathrm{H}^{+}$species in solution, which causes an increase in the electrical conductivity of the solution, and an enhancement of the reaction between the generated free electrons during plasma generation with the $\mathrm{MB}$ solution (reaction in Eq. 3). This factor could improve the $\mathrm{H}_{2} \mathrm{O}_{2}$ production rate [28].

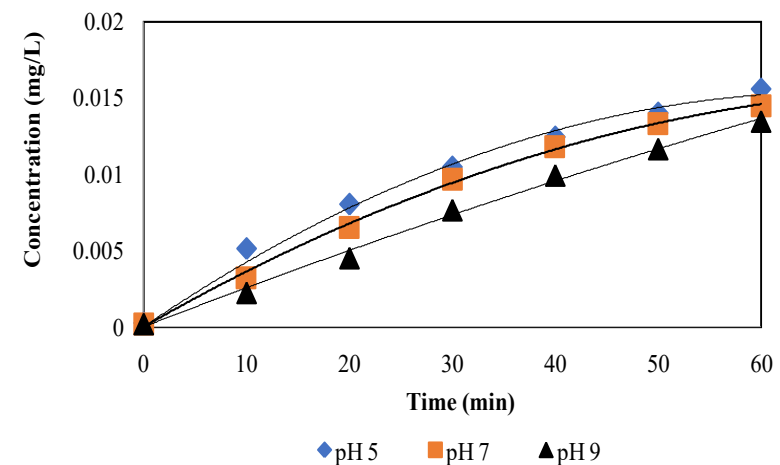

Fig. 5. (Color online) Influence of $\mathrm{MB}$ solution $\mathrm{pH}$ on $\mathrm{H}_{2} \mathrm{O}_{2}$ concentration.

\subsection{Degradation of MB concentration}

To observe the degradation efficiency of the $\mathrm{MB}$ concentration after Ar-NTP treatment in the previous section, the MB solutions were analyzed by recording their UVvisible spectra. Fig. 6 presents the UV-visible spectra of the untreated and treated $\mathrm{MB}$ solution with the initial $\mathrm{MB}$ concentration of $5 \mathrm{mg} / \mathrm{L}$. The experiment conditions for the treated MB solution were $20.35 \mathrm{~W}$ plasma power and 4 LPM Ar gas flow rate. The absorbance of the treated MB solution decreased after Ar-NTP treatment for $60 \mathrm{~min}$. Here, the spectra of MB showed strong absorption peaks in the visible spectral region with $\lambda_{\max }$ at $660 \mathrm{~nm}$ and in the other two spectra in the UV region with $\lambda_{\max }$ at 291 and $246 \mathrm{~nm}$. The peaks at $660 \mathrm{~nm}$ correspond to $\mathrm{n}-\pi^{*}$ transitions ( $\mathrm{n}$ is the free doublet on the nitrogen atom of a $\mathrm{C}=\mathrm{N}$ bond and the free doublet of a $\mathrm{S}$ atom on a $\mathrm{S}=\mathrm{C}$ bond). Other peaks at 291 and $246 \mathrm{~nm}$ correspond to $\pi-\pi *$ transitions of the benzene ring. After Ar-NTP treatment for $60 \mathrm{~min}$, the peak intensity at 660 , 291, and $246 \mathrm{~nm}$ decreased. This confirmed that the Ar-NTP treatment could enhance the degradation of MB. The MB degradation mechanism could be explained as following two pathways [28], [30], [32]. The first pathway is where high energetic electrons react with $\mathrm{MB}$ molecules, resulting in breaking down the chemical bonds in $\mathrm{MB}$; for example, the $\mathrm{N}-\left(\mathrm{CH}_{3}\right)_{2}$ group is broken down to form an $-\mathrm{N}-\mathrm{H}\left(\mathrm{CH}_{3}\right)$ group. The second pathway is where $\bullet \mathrm{OH}$ reacts with $\mathrm{MB}$ molecules, resulting in breaking down the structural rings of $\mathrm{MB}$ molecules at the $\mathrm{C}-\mathrm{S}$ and $\mathrm{C}-\mathrm{N}$ bonds, causing the $\mathrm{MB}$ molecule to become two-parts of small molecules [33].

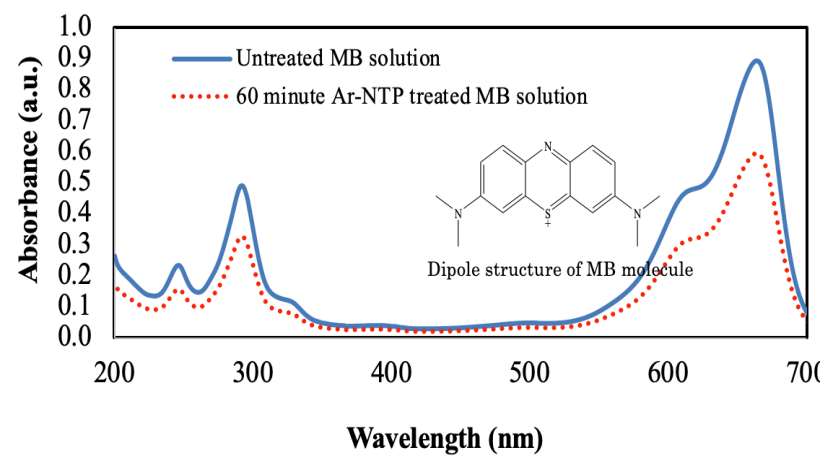

Fig. 6. (Color online) UV-visible spectra of MB aqueous solution before and after $60 \mathrm{~min}$ Ar-NTP treatment.

Fig. 7a shows the results of the effect of $\mathrm{pH}$ on the decrease in $\mathrm{MB}$ concentration. At a treatment time of $60 \mathrm{~min}$, the remaining concentration of $\mathrm{MB}$ at $\mathrm{pH} 5$ was the lowest.

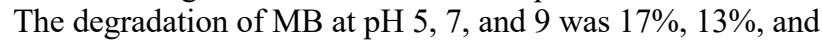
$10 \%$, respectively. These low degradations of MB may be due to the low plasma power. To determine the degradation rate constant of $\mathrm{MB}$, the experimental results from Fig. 7a were plotted as a function of $\ln \left(\mathrm{C}_{\mathrm{MB}}\right)$ and the treatment time, where $\mathrm{C}_{\mathrm{MB}}$ is the methylene blue concentration. The slopes of each plot represent the degradation rate constants of $\mathrm{MB}$, which are presented in Fig. 7b. It was found that at a low $\mathrm{pH}$, the degradation rate constant was higher than that at a high $\mathrm{pH}$. The degradation rate constants at $\mathrm{pH} 5, \mathrm{pH} 7$, and $\mathrm{pH} 9$ were $8.6 \times 10^{-3}, 5.90 \times 10^{-3}$, and $4.20 \times 10^{-3} \mathrm{~min}^{-1}$, respectively. The degradation rate constant at $\mathrm{pH} 5$ was about two times the degradation rate constant at $\mathrm{pH}$ 9. At a lower $\mathrm{pH}$, the generation rate of $\mathrm{H}_{2} \mathrm{O}_{2}$, which plays an important role in $\mathrm{MB}$ degradation, was higher than that at the higher $\mathrm{pH}$ [34]. The MB degradation followed a pseudo-first-order reaction caused by the reaction between the high energetic electron, the hydroxyl radical $(\bullet \mathrm{OH})$, and $\mathrm{H}_{2} \mathrm{O}_{2}$ with the $\mathrm{MB}$ molecule [28].

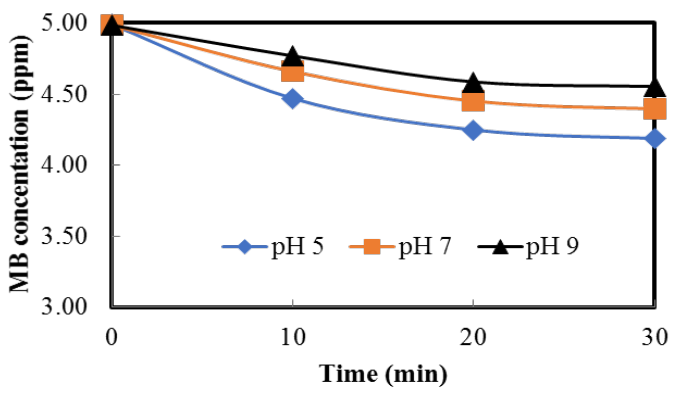

(a) 


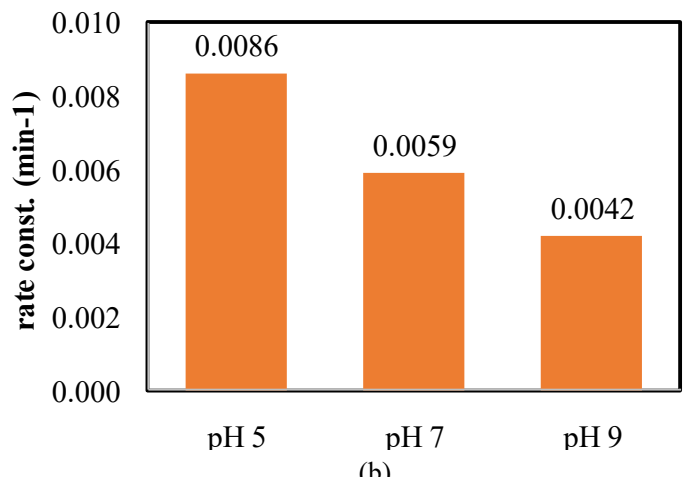

Fig. 7. (Color online) a) Concentration of $\mathrm{MB}$, and b) the reaction rate of degradation of MB at various $\mathrm{pH}$ values after Ar-NTP treatment.

3.5 MB degradation enhancement by the addition of $\mathrm{Fe}^{2+}$ The effect of the addition of $\mathrm{Fe}^{2+}$ on $\mathrm{MB}$ degradation enhancement was studied. $\mathrm{Fe}^{2+}$ was added to the $\mathrm{pH} 5 \mathrm{MB}$ solution with an initial MB concentration of $5 \mathrm{ppm}$. Ar-NTP treatment was performed at a plasma power of $20.35 \mathrm{~W}$ and Ar gas flow rate of 4 LPM. Fig. 8a presents the degradation rate constant of $\mathrm{MB}$ with various $\mathrm{Fe}^{2+}$ concentrations (0-3680 $\mathrm{mg} / \mathrm{L})$. The degradation rate constant linearly increased with increasing the concentration of the added $\mathrm{Fe}^{2+}$. It was noticed that the degradation rate constant seemed to become saturated at $83.7 \times 10^{-3} \mathrm{~min}^{-1}$ when the addition concentration of $\mathrm{Fe}^{2+}$ was more than $920 \mathrm{mg} / \mathrm{L}$. Therefore, the proper addition amount of $\mathrm{Fe}^{2+}$ for optimized $\mathrm{MB}$ degradation in this experiment was determined to be $920 \mathrm{mg} / \mathrm{L}$. Fig. 8b illustrates the MB solutions with a 5 ppm initial MB concentration after Ar-NTP treatment at the different treatment times of $0,10,20,30,40$, 50 , and $60 \mathrm{~min}$.
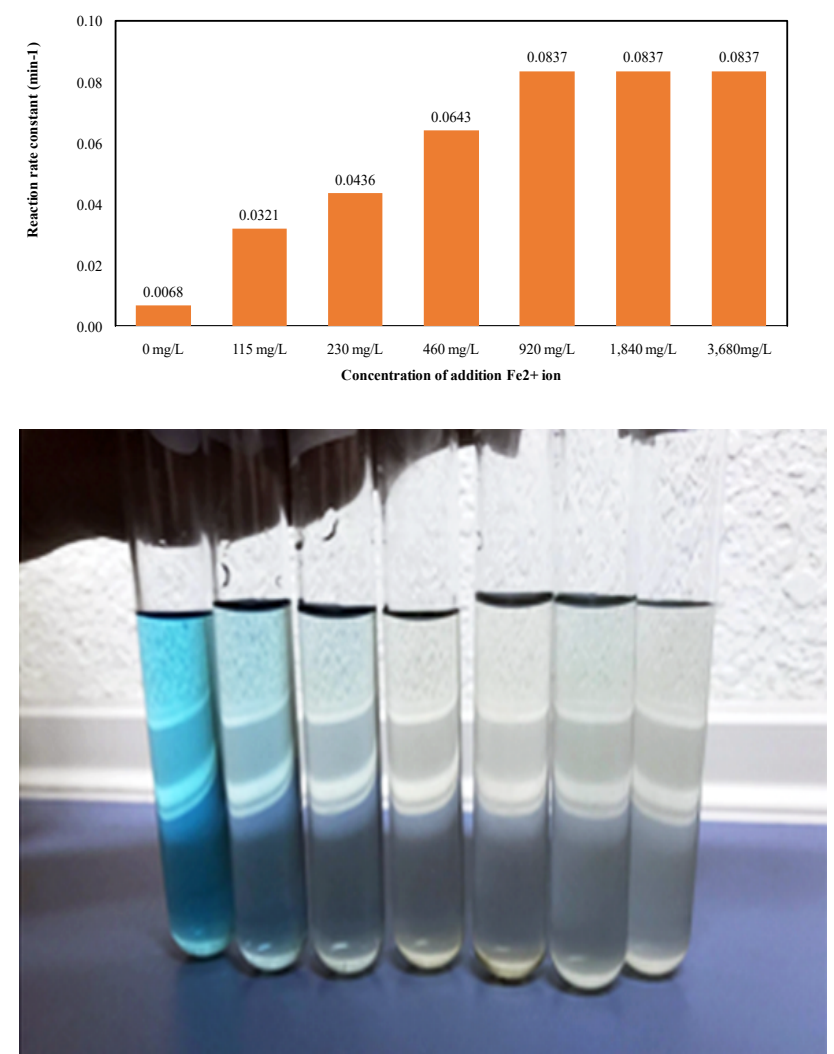

Fig. 8. (Color online) a) Degradation rate constant of $M B$ with the addition of $\mathrm{Fe}^{2+}$ at various initial $\mathrm{MB}$ concentrations, and b) MB solutions with $5 \mathrm{ppm}$ of initial MB concentration after Ar-NTP treatment at different treatment times: $0,10,20,30,40,50$, and $60 \mathrm{~min}$ (from left to right). The Ar-NTP treatments were performed at a plasma power of $20.35 \mathrm{~W}, 4 \mathrm{LPM}$ Ar gas flow rate, and $\mathrm{pH} 5$ for the MB solution.
In the Fenton process, $\mathrm{H}_{2} \mathrm{O}_{2}$ can be easily decomposed to $\bullet \mathrm{OH}$ in the presence of $\mathrm{Fe}^{2+}$ ions. The $\mathrm{Fe}^{2+}$ ion reacts with $\mathrm{H}_{2} \mathrm{O}_{2}$ to form $\bullet \mathrm{OH}$ and $\mathrm{Fe}^{3+}$, as shown in the reaction in Eq. 12-14 [35]. The generated $\mathrm{Fe}^{3+}$ then reacts with $\mathrm{H}_{2} \mathrm{O}_{2}$ to form $\bullet \mathrm{OH}$ and perhydroxide radical $(\bullet \mathrm{OOH})$ [36-37]. Here, $\bullet \mathrm{OH}$ is a stronger oxidizing agent for $\mathrm{MB}$ degradation than $\mathrm{H}_{2} \mathrm{O}_{2}$. Therefore, the addition of $\mathrm{Fe}^{2+}$ into the $\mathrm{MB}$ solution would improve the degradation rate of $\mathrm{MB}$.

$$
\mathrm{Fe}^{2+}+\mathrm{H}^{+}+\mathrm{H}_{2} \mathrm{O}_{2} \rightarrow \mathrm{Fe}^{3+}+\mathrm{H}_{2} \mathrm{O}+\bullet \mathrm{OH}
$$

$$
\mathrm{Fe}^{2+}+\mathrm{H}_{2} \mathrm{O}_{2} \rightarrow \mathrm{Fe}^{3+}+\mathrm{OH}^{-}+\bullet \mathrm{OH}
$$

$\mathrm{Fe}^{3+}+\mathrm{H}_{2} \mathrm{O}_{2} \rightarrow \mathrm{Fe}^{2+}+\bullet \mathrm{OOH}+\mathrm{H}^{+}$

(14)

To determine the effect of the initial concentration of MB on the degradation rate constant, the initial concentration of $\mathrm{MB}$ was varied at 5,10,15, and $20 \mathrm{ppm}$. Ar-NTP treatment was performed for $60 \mathrm{~min}$ at $20.35 \mathrm{~W}$ plasma power, $4 \mathrm{LPM}$ Ar gas flow rate, $\mathrm{pH} 5$, and with the addition of $920 \mathrm{mg} / \mathrm{L}$ of $\mathrm{Fe}^{2+}$. From the experimental results, the degradation rate constant of MB was seen to decrease with the increase in the initial MB concentration, as depicted in Fig. 9. The degradation rate constants for the initial concentrations of $\mathrm{MB}$ at $5,10,15$, and $20 \mathrm{ppm}$ were $0.0551,0.279,0.0182$, and $0.0119 \mathrm{~min}^{-1}$, respectively. This could imply that a high initial concentration of $\mathrm{MB}$ needs more treatment time for the plasma treatment [38].

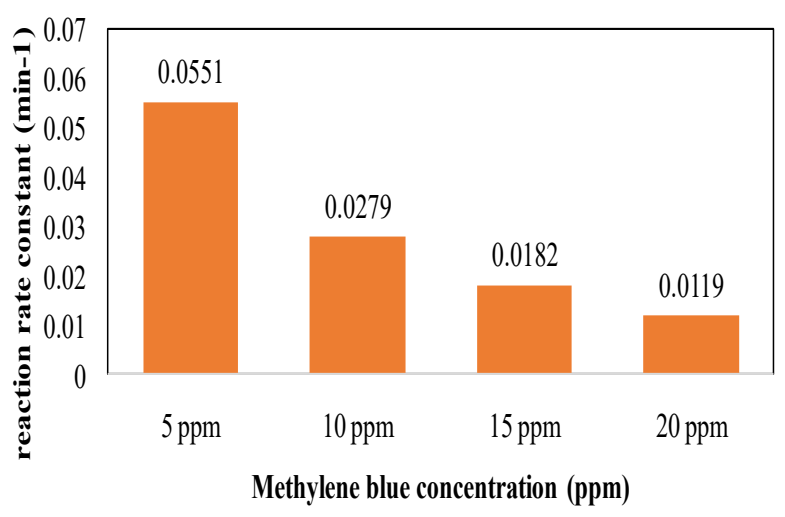

Fig. 9. (Color online) Degradation rate constant of MB with the addition of $920 \mathrm{mg} / \mathrm{L} \mathrm{Fe}^{2+}$ ions at various initial MB concentrations.

\section{Conclusions}

An investigation was carried out into the influence of Ar nonthermal plasma (Ar-NTP) on the decolorization of methylene blue (MB) and the results presented herein. It was confirmed that the flow rate of Ar gas and the plasma power significantly affected the production of hydrogen peroxide $\left(\mathrm{H}_{2} \mathrm{O}_{2}\right)$. The results showed that increasing the $\mathrm{Ar}$ gas flow rate and the plasma power resulted in an increase in $\mathrm{H}_{2} \mathrm{O}_{2}$ production. Also, the production of $\mathrm{H}_{2} \mathrm{O}_{2}$ was greater at lower $\mathrm{pH}$. The decolorization rate constant of $\mathrm{MB}$ followed a pseudo-firstorder reaction, and decreased with the increase in solution $\mathrm{pH}$. The addition of $\mathrm{Fe}^{2+}$ ions could enhance the decolorization rate of MB. The optimum experimental conditions for the decolorization of a $5 \mathrm{ppm}$ initial $\mathrm{MB}$ concentration without the addition of $\mathrm{Fe}^{2+}$ were $20.35 \mathrm{~W}$ plasma power, 4 LPM Ar 
gas flow rate, and $\mathrm{pH} 5$, which resulted in a decolorization rate of $8.6 \times 10^{-3} \mathrm{~min}^{-1}$. Whereas, the decolorization rate increased 9.73 times when $920 \mathrm{ppm}$ of $\mathrm{Fe}^{2+}$ was added to the MB solution.
This is an Open Access article distributed under the terms of the Creative Commons Attribution License

\section{References}

1) K. Takahashi, K. Takaki, and N. Satta, J. Adv. Oxid. Technol. 15, (2012).

2) J. Liu, B. He, Q. Chen, J. Li, Q. Xiong, G. Yue, X. Zhang, S. Yang, H. Liu, and Q. H. Liu, Scientific Reports 6, (2016).

3) J. Gao, Pak. J. Biol. Sci. 9, 323 (2006).

4) T. C. Shih, M. Wangpaichitr, and M. Suffet, Water Research 37, 375 (2003).

5) B. Jiang, J. Zheng, S. Qiu, M. Wu, Q. Zhang, Z. Yan, and Q. Xue, Chem. Eng. J. 236, 348 (2014).

6) J.P. Bruggeman and D.C. Schram, Plasma Sources Sci. Technol. 19, 045025 (2010).

7) D.B. Graves, J. Phys. D 45, 263001 (2012).

8) N. Khamsen, O. Damrongvudhi, T. Nithiphat, S. Dechanupaprittha, W. Kanokbannakorn, K. Hongesombut, and S.Srisonphan. ACS Appl Mater. Interfaces 8, 19268 (2016).

9) B. Jiang, J. Zheng, S. Qiu, M. Wu, Q. Zhang, Z. Yan, and Q. Xue, Chem. Eng. J. 236, 348 (2014).

10) Y. Gorbanev, D. Oconnell, and V. Chechik, Chem. Eur. J. 22, 3496 (2016).

11) T.G. Klampfl, G. Isbary, T. Shimizu, Y.-F. Li, J.L. Zimmermann, W. Stolz, J. Schlegel, G.E. Morfill, and H.-U. Schmidt, Appl. Environ. Microbiol. 78, 5077 (2012).

12) S. Theepharaksapan and K. Matra, The 2018 International Electrical Engineering Congress (iEECON2018), IEEE, (2018). [in Press]

13) C. Dechthummarong and K. Matra, The 2018 International Electrical Engineering Congress (iEECON2018), IEEE, (2018). [in Press]

14) H.H. Cheng, S.S. Chen, Y.C. Wu, and D.L. Ho. J. Environ. Eng. Manage. 17, 427 (2007).

15) S. Katsuki, K. Tanaka, T. Fudamoto, T. Namihira, H. Akiyama, and H. Bluhm, Jpn. J. Appl. Phys. 45, 239 (2006).

16) X. Liao, D. Liu, Q. Xiang, J. Ahn, S. Chen, X. Ye, and T. Ding, Food Control 75, 83 (2017).

17) K. Panngom, S.H. Lee, D.H. Park, G.B. Sim, Y.H. Kim, H.S. Uhm, G. Park, and E.H. Choi, PLOS ONE 9, (2014).

18) R. Nogueira, M. Oliveira, and W. Paterlini, Talanta 66, 86 (2005).
19) M. S. Mahadevaiah, A. Galil, M. S. Y. Kumar, M. A. Sathish, and G. Nagendrappa, J. Anal. Chem. 63, 239 (2008).

20) K. Matra, Jpn. J. Appl. Phys. 57, (2017).

21) R. Morrow, J. Phys. D 30, 3099 (1997).

22) R. Ono, Y. Nakagawa, and T. Oda, J. Phys. D 44, 485201 (2011).

23) H. Taghvaei and M.R. Rahimpour, RSC Adv. 6, 98369 (2016).

24) C. Lazzaroni and P. Chabert, Plasma Sources Sci. Technol. 20, 055004 (2011).

25) K. Matra, H. Furuta, and A. Hatta, J. Phys.: Conf. Ser. 441, 012021 (2013).

26) J. Choi, K. Matsuo, H. Yoshida, T. Namihira, S. Katsuki, and H. Akiyama, Jpn. J. Appl. Phys. 47, 6459 (2008).

27) K. Matra, Jpn. J. Appl. Phys. 55, 07LB02 (2016).

28) L. O. D. B. Benetoli, B. M. Cadorin, V. Z. Baldissarelli, R. Geremias, I. G. D. Souza, and N. A. Debacher, J. Hazard. Mater. 237-238, 55 (2012).

29) C. A. Vasko, D. X. Liu, E. M. V. Veldhuizen, F. Iza, and P. J. Bruggeman, Plasma Chem Plasma Process 34, 1081 (2014).

30) M. Magureanu, C. Bradu, D. Piroi, N. B. Mandache, and V. Parvulescu, Plasma Chem Plasma Process 33, 51 (2013).

31) A.A. Joshi, B.R. Locke, P. Arce, and W.C. Finney, J. Hazard. Mater. 41, 3 (1995).

32) H. Ghodbane, O. Hamdaoui, J. Vandamme, J. V. Durme, P. Vanraes, C. Leys, and A. Y. Nikiforov, Open Chem. 13, 325 (2015).

33) G. R. Dey and T. N. Das, Plasma Chem. Plasma Process. 36, 523 (2015).

34) Y. Wen, J. Yi, S. Zhao, S. Jiang, Y. Chi, and K. Liu, J. Environ. Sci. 44, 99 (2016).

35) S. Yang, H. He, D. Wu, D. Chen, X. Liang, Z. Qin, M. Fan, J. Zhu, and P. Yuan, Appl. Catal., B 89, 527 (2009).

36) L. Tengrui, A. Al-Harbawi, Z. Jun, and L. M. Bo, J. Appl. Sci. 7, 724 (2007).

37) A. Bach, H. Shemer, and R. Semiat, Desalination 264, 188 (2010).

38) R. F. Quadrado and A. R. Fajardo, Carbohydr Polym. 177, 443 (2017). 